Binghamton University

The Open Repository @ Binghamton (The ORB)

$1-31-2017$

\title{
Analysis for Science Librarians of the 2016 Nobel Prize in Physiology or Medicine: The Life and Work of Yoshinori Ohsumi
}

Neyda Gilman

ngilman@binghamton.edu

Follow this and additional works at: https://orb.binghamton.edu/librarian_fac

Part of the Biology Commons, Cell and Developmental Biology Commons, and the Library and Information Science Commons

\section{Recommended Citation}

Neyda V. Gilman (2017): Analysis for Science Librarians of the 2016 Nobel Prize in Physiology or Medicine: The Life and Work of Yoshinori Ohsumi, Science \& Technology Libraries, DOI: 10.1080/ $0194262 X .2016 .1273814$

This Article is brought to you for free and open access by the University Libraries at The Open Repository @ Binghamton (The ORB). It has been accepted for inclusion in Library Scholarship by an authorized administrator of The Open Repository @ Binghamton (The ORB). For more information, please contact ORB@binghamton.edu. 


\title{
Analysis for Science Librarians of the 2016 Nobel Prize in Physiology or Medicine: The Life and Work of Yoshinori Ohsumi
}

\begin{abstract}
Autophagy is a cellular process of destruction and recycling. Cellular materials are broken down and recycled as needed, providing the body a way to remove unwanted material while also providing the means to create new needed items. The importance of this process and its possible role in numerous diseases is why Yoshinori Ohsumi has been awarded a 2016 Noble Prize. Ohsumi has been awarded the 2016 Nobel in Physiology or Medicine for his "discoveries of mechanisms for autophagy" and thus paving the way for the exciting field of autophagy research ” (Nobelprize.org 2016a).
\end{abstract}

KEYWORDS 2016 Nobel Prize in Physiology or Medicine, Yoshinori Ohsumi, Autophagy, Nobel

\section{INTRODUCTION}

Autophagy is the process of cellular "self-eating" in eukaryotic cells that mediates the removal of material from the cytoplasm and is considered responsible for the bulk removal of material, including proteins (Larsson and Masucci 2016). There are two branches of the autophagic process: macro and micro. Both branches utilize specific organelles for the actual breakdown of cellular materials. Organelles are cellular items that play a specialized role in the cell, comparable to an organ in a body. In animals, lysosomes are the organelles that play the final role in autophagy, whereas in organisms without lysosomes such as yeast, vacuoles fulfil the role 
(Wiemken, Schellenberg, and Urech 1979). In regards to the two processes of autophagy, microautophagy is when a cellular component that needs to be destroyed is independently brought into a lysosome or vacuole by fusing directly with that organelle’s membrane. Macroautophagy involves components being sequestered in bulk within a body called an autophagosome before being delivered to a lysosome or vacuole, where they are broken down (Ohsumi 2014). Macroautophagy is what is usually referred to when discussing autophagy, and what the term autophagy will refer to in the remainder of this article.

On 3 October 2016, Dr. Yoshinori Ohsumi was awarded the 107th Nobel Prize in Physiology or Medicine for his work resulting in “discoveries of mechanisms for autophagy” (Nobelprize.org “Press release: The 2016 Nobel Prize in Physiology or Medicine.”). This work resulted in, and was deemed worthy of, the Nobel honor because it has resulted in new knowledge, techniques, and ideas to explore the critical role autophagy plays in human health and function. Ohsumi began his work looking at cellular "waste dumps” over a quarter of a century ago and in 1992 published an article that broke through the somewhat stagnant autophagy research. In this article he isolated yeast vacuoles using a technique his lab had developed a decade before, observed autophagy microscopically, and then identified the first fifteen genes of many that play a role in the autophagy process (Takeshige et al. 1992). This award makes Ohsumi the 211th Physiology or Medicine Laureate and only the 39th solo recipient of the award (Nobelprize. org "Press release: The 2016 Nobel Prize in Physiology or Medicine.”).

In an interview after the announcement of the award, a member of the Nobel Committee for Physiology or Medicine, Professor Juleen Zierath, described autophagy as a recycling process (Nobelprize.org “Prize announcement: The Nobel Prize in Physiology or Medicine 2016.”). She stated that the lysosome or vacuole, where autophagy concludes, was once seen as a waste dump 
in the cell, but it is more accurately a recycling plant that allows organisms, including humans, to reuse proteins so as to not be completely dependent on consuming all the proteins needed by the body. Amino acids are broken down and recycled to produce new proteins or energy (ATP) and possibly glucose, although no studies have yet confirmed this. Autophagy also plays a role in organelle turn- over, which protects the cell. This role is important for cellular health, and research has suggested that defective processes may lead to disease such as cancer or Parkinson's disease (Kuma and Mizushima 2010).

\section{THE SCIENCE}

\section{SOME BACKGROUND}

The lysosome, the primary organelle involved in Animalia eukaryotic autophagy, was discovered almost forty years before Ohsumi’s findings. In 1955, Christian de Duve discovered and named the lysosome. This discovery led to de Duve earning one third of the 1974 Nobel Prize in Physiology or Medicine, which was awarded for “discoveries concerning the structural and functional organization of the cell” (Nobelprize.org “Christian de Duve-Facts.”). De Duve’s identification of the lysosome effectively marked the beginning of autophagy research. The lysosome was originally viewed as a granule that contained enzymes and acted as the cellular “digestive tract,” digesting material from both within and with- out the cell (de Duve et al. 1955;

de Duve and Wattiaux 1966). Research on lysosomes and their role continued, and lysosomes were classified as organelles. Later research revealed that lysosomal enzymes, specifically hydro- lases, were key in the chemical breakdown of tissues (de Duve 1963). It was also observed that at times lysosomes contained multiple cellular components, sometimes even complete organelles, including large mitochondria (Nobelprize.org "Press release: The 2016 
Nobel Prize in Physiology or Medicine.”). These findings, along with questions on large protein degradation raised by research in ubiquitin and proteasomes, alluded to an unknown process that moved material of all sizes from the cytosol to within the lysosome for degradation. Through microscopy and biochemical analysis, a basic understanding of the process was discovered, and a new transportation vesicle was identified. In 1963, eight years after his discovery of the lysosome, de Duve coined the term autophagy due to the self-eating nature of the process (de Duve 1963). A few years later, referring to a phagosome in the "autophagic line," he merged the phagosome and autophagy, forming the term autophagosome for the transportation vesicle (de Duve and Wattiaux 1966).

De Duve set the foundation for Ohsumi's work, but he wasn't the only one. After de Duve's discoveries, but before Ohsumi, scientists in the 1970s and 1980s explored how proteins were degraded. Three scientists, Ciechanover, Hershko, and Rose, discovered “ubiquitin-mediated protein degradation” within proteasomes and were awarded the 2004 Nobel Prize in Chemistry for the discovery (Nobelprize.org “Press release: The Nobel Prize in Chemistry 2004.”). This discovery explained unanswered questions in regards to regulated degradation of proteins, but it also created questions regarding the breakdown of large proteins and other cellular components. The answer to these questions turned out to be autophagy.

There was additional work happening before, and concurrently with, Ohsumi’s research. In his 2014 autophagy review entitled “Historical Landmarks of Autophagy Research,” Ohsumi states that between the time of de Duve's work and his own, the following occurred: G. Mortimore published on the inhibition of autophagy by amino acids and insulin in 1976; P. Seglen identified an important autophagy inhibitor called 3-methyladenine in 1982; and J. F. Dice discovered chaperon-mediated autophagy in 1985. Around the same time that Ohsumi was observing 
autophagy in yeast and identifying genes, at least two other scientists were researching autophagy genes. Two years after Ohsumi’s publication, Thumm et al. (1994) published their research on genes that play a role in autophagy in yeast. D.J. Klionsky is another scientist whose work added to the foundation of Ohsumi's work. A review of Klionsky's publications in Web of Science on November 9, 2016, revealed that he worked on protein sorting in vacuoles/ lysosomes as well as also working on autophagy-related genes. A main focuses of Klionsky's has been the Cvt pathway (cytoplasm-to-vacuole transport pathway), a pathway similar to autophagy that results in the direct delivery of hydrolases $\alpha$-aminopeptidase I and $\alpha$-mannosidase from the cytoplasm to the vacuole (Hutchins and Klionsky 2001; Ohsumi 2014).

Ohsumi's work resulted in the identification of autophagy-related genes in yeast, which were named apg (later changed to aut) while similar genes, using the Cvt naming schema, were discovered in the Cvt pathway. Comparison of these two gene groups show that the two pathways have some genetic overlap, but they are two separate pathways (Harding et al. 1996). This pathway is often discussed and compared with autophagy in autophagy-related research.

\section{AUTOPHAGY}

Autophagy has been referred to as a “mirror image of phagocytosis” (de Duve and Wattiaux 1966). In phagocytosis, a phagocyte envelopes invading material such as a bacterium and removes it before it can do harm. Autophagy works in a similar way, with material being enveloped by a vesicle for it to be removed. The difference is that autophagy typically works on the "self," such as cellular proteins and organelles, and the material that is to be removed is often recycled rather than merely destroyed. Double-membraned autophagosomes form in the cytosol, engulfing whatever material needs to be destroyed, then fuse with lysosomes or vacuoles, 
resulting in a single-membraned autophagic body inside the organelle (Baba et al. 1994). The formation of the autophagosome, what comes before it, and how the double membrane is formed, is still unknown (Yamamoto et al. 2016). This question has interested researchers for years. One theory, dating back to 1968, is that the preautophagosomal structure is formed from the smooth endoplasmic reticulum (Arstila and Trump 1968). More recent research states a de novo formation of a membrane, which becomes spherical and eventually seals with itself, after enclosing the cellular material to be destroyed, to become the autophagosome (Nakatogawa et al. 2009).

Another of the earliest questions about autophagy was how it works in regards to what is collected in the autophagosome and taken to the lysosome. In the same article where he coined the term autophagy, de Duve reviews the rates at which material is destroyed by autophagy and determines that random bulk autophagy does not make sense (de Duve and Wattiaux 1966). Early experiments confirmed this and showed that autophagy is induced by cell starvation. This is observed in research showing an induction of autophagy by glucagon, a hormone that is naturally released when blood sugar drops, and an inhibition of autophagy by insulin, a hormone found with high blood sugar, as well as in research such as Ohsumi’s where yeast is grown on nutrient-deprived media (Arstila and Trump 1968; Deter, Baudhuin, and de Duve 1967; Pfeifer and Warmuth-Metz 1983; Takeshige et al. 1992). Other research has noted that the breakdown of proteins through the autophagy process is dependent on amino acid levels, with different amino acids inducing and suppressing the process (Mortimore, Hutson, and Surmacz 1983; Mortimore and Ward 1975). Growth factors and an increase in nutrients have been shown to inhibit autophagy through the target of rapamycin, TOR kinase (Levine and Kroemer 2008). 
Early research on autophagy has focused on the nonselective process where autophagosomes are induced and collect bulk cytosolic materials including proteins and organelles to be taken to the lysosome for degradation. This induction of autophagy is attributed to a state of starvation or stress, when the breakdown and recycling of cellular material to make new materials needed by the cell immediately makes sense (Ohsumi 2014). More recent research has shown that there is also a method for selective autophagy where specific items are collected for destruction (Nakatogawa et al. 2009). Selective autophagy involves removal of items, including damaged organelles, bacteria, and other harmful or unnecessary materials. See Figure 1 for a representation of both selective and nonselective (starvation-induced) autophagy.

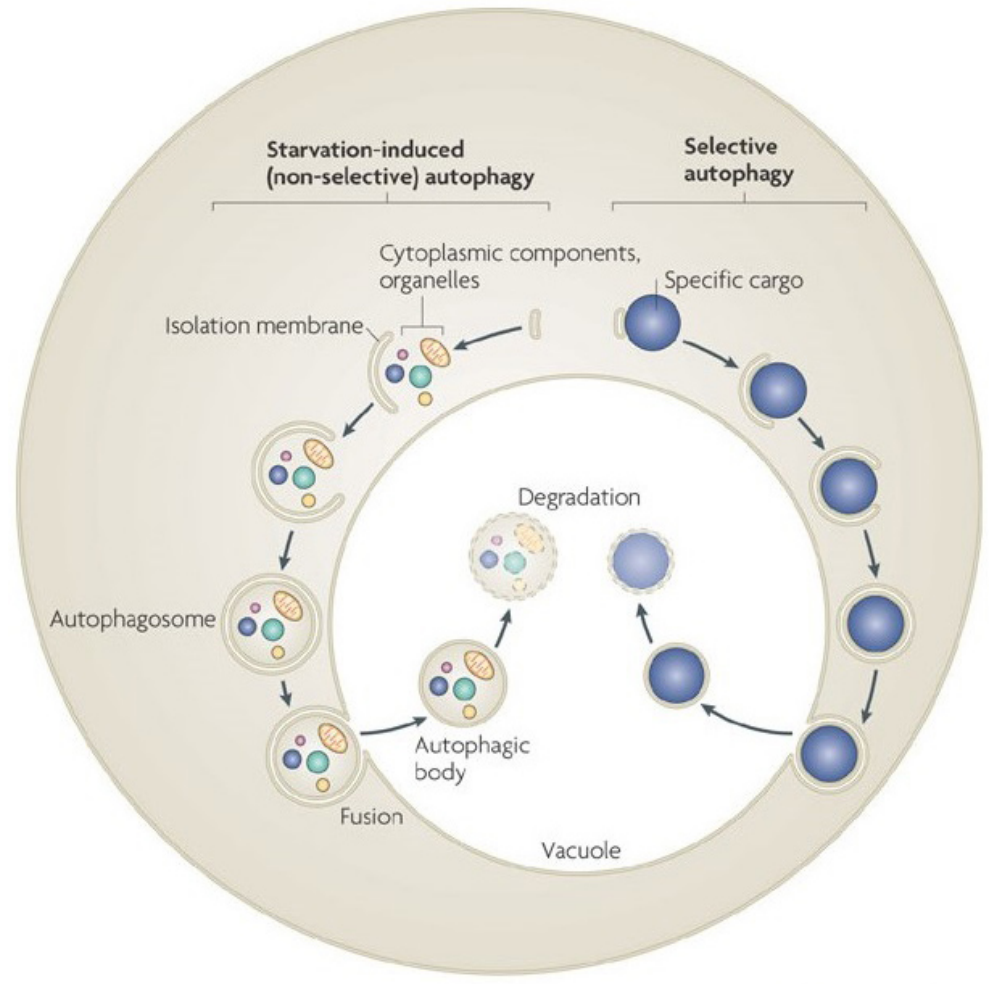

FIGURE 1 Image representing selective and non-selective (starvation induced) autophagy (Reprinted by permission from Macmillan Publishers Ltd: Nature "Dynamics and diversity in autophagy mechanisms: lessons from yeast,” (c) 2009.) 


\section{OHSUMI'S WORK}

Fifty years had passed between the discovery of autophagy and Ohsumi's work, but it was only after Ohsumi that the critical role autophagy plays in health was recognized (Nobelprize.org “Press release: The 2016 Nobel Prize in Physiology or Medicine.”). Prior to the 1990s it was known that cells had “waste dumps,” but the autophagy process and machinery were unknown, as was any correlation with disease (Nobelprize.org "Prize announcement: The Nobel Prize in Physiology or Medicine 2016.”). Before Ohsumi, the scientific knowledge of autophagy came from examination of mammalian cells using electron microscopy, and much about autophagy was unknown due to the complexities of mammalian lysosomes. Ohsumi used yeast for his research in part due to vacuoles being more easily isolated from yeast cells than lyso- somes are from animal cells (Takeshige et al. 1992). Studying autophagy in yeast has additional benefits: The autophagic process of the cells occurs en masse in a consistent environment; it allows for easy determination of the autophagolysosomal stage (where the autophagosome membrane fuses with the lysosome membrane) by looking at the accumulation of autophagic bodies; and it is easy to isolate various mutants that facilitate genetic experimentations (Tsukada and Ohsumi 1993). It was hypothesized that the yeast system used by Ohsumi and Takeshige could be used to learn more about autophagic signal transduction and intracellular membrane flow.

The research that was at the beginning of Ohsumi’s success was published in his 1992 article “Autophagy in Yeast Demonstrated with Proteinase-Deficient Mutants and Conditions for Its Induction” (Takeshige et al. 1992). In the experiments that led to this article, yeast cells lacking vacuolar proteases were grown in YEPD, a nutrient-rich medium containing yeast extract, polypepton, and glucose. The cells were then moved to a nutrient- (nitrogen) deficient medium, which halted the growth of the cells and showed the gradual increase in spherical bodies within 
the vacuoles of the cells. This was done with a variety of yeast strains that were selected due to their deficiency in vacuolar proteinases, enzymes that break down proteins. These deficiencies prevented cellular com- ponents from being degraded as usual in the vacuoles. Using light microscopy, Ohsumi and his team saw an accumulation of these bodies within the vacuoles. In addition to various yeast strains being observed, the yeasts were grown in a range of media, each with different nutritional deficiencies (carbon, glycerol, various amino acids, etc.). Most of the media grew cells with an accumulation of bodies in the vacuoles, but the amount of accumulation varied. Some had no accumulation of bodies but still halted growth of the cells. The cells were also observed using electron microscopy, which resulted in images that showed the bodies in all stages of cell growth and suggested that the bodies were made up of cytosolic components (see Figure 2). These bodies were named “autophagic bodies” based on the conclusion that they were a result of autophagy. 


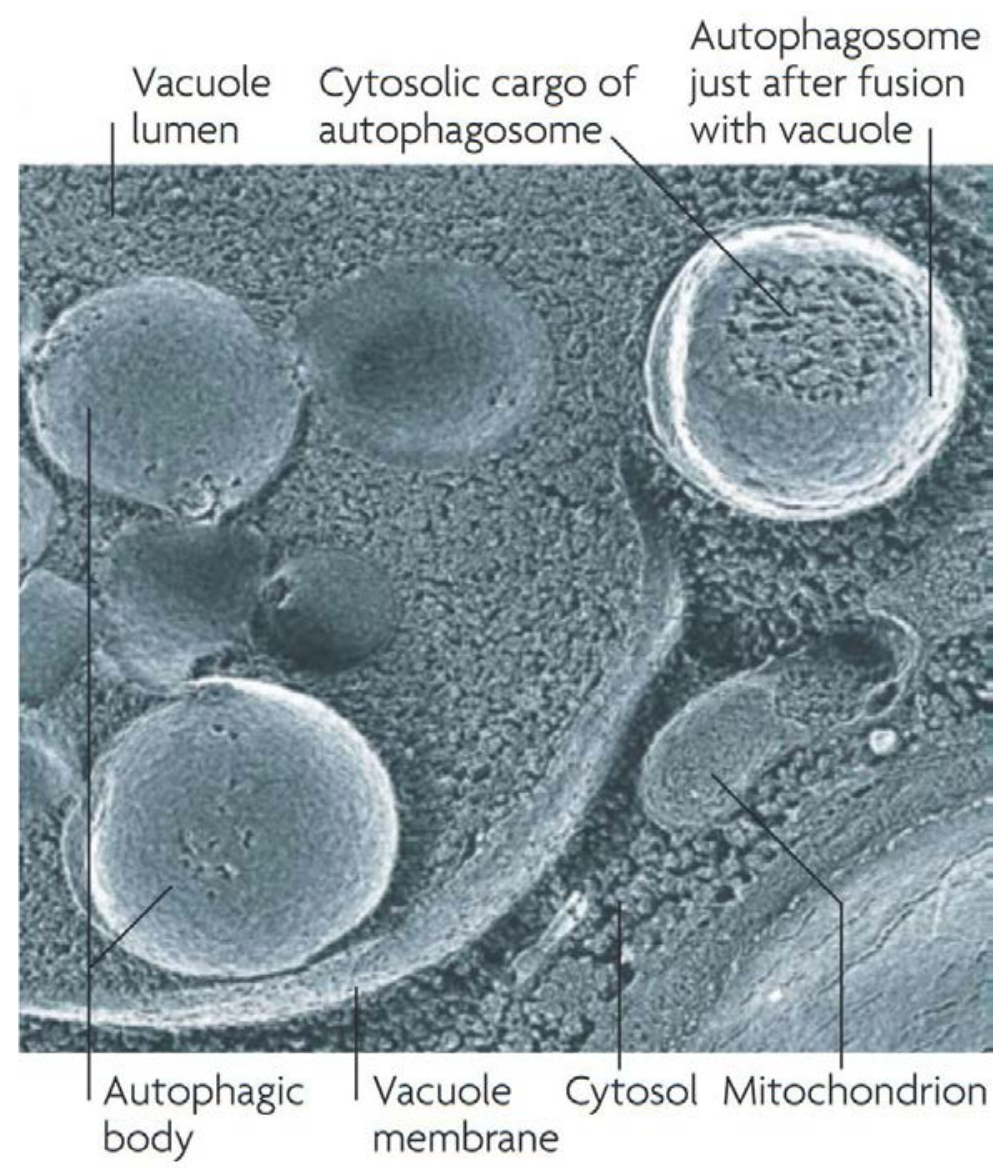

FIGURE 2 Autophagy in a yeast cell visualized by electron microscopy. (Reprinted by permission from Macmillan Publishers Ltd: Nature “Autophagy: from phenomenology to molecular understanding in less than a decade,” (C) 2007.)

Ohsumi's groundbreaking research went beyond identifying and observing autophagy in yeast. As described in the same 1992 article (Takeshige et al. 1992), he and his colleagues went on to examine the strains of yeast and identified genes critical to autophagy. In their research, a yeast strain that was deficient in multiple vacuolar proteases was crossed with wild-type cells to form mutants that were lacking a single vacuolar protease. Analysis of these mutant strains suggested that a specific gene, the PRB1 gene that leads to proteinase $B(\operatorname{PrB})$, plays a role in the 
breakdown of autophagic bodies, since these bodies accumulated in the absence of PrB activity. Continued experimentation with different yeast strains in different media, including PMSF (a protease inhibitor), provided support for the concept that autopha- gic bodies naturally degrade in the cell vacuoles fairly quickly. This finding showed that the accumulation of autophagic bodies in vacuoles is abnormal and would occur only if a part of the autophagy process was disabled, opening the way to further genetic investigations.

This research is considered a breakthrough due in part to the challenges that needed to be overcome (Nobelprize.org “Press release: The 2016 Nobel Prize in Physiology or Medicine.”). According to Takeshige et al. (1992) a major challenge that had prevented the previous use of yeast to study autophagy was that of isolating the yeast vacuole. Using a technique he and colleagues developed in 1981, Ohsumi was able to isolate the vacuoles and observe autophagy microsco- pically. Other challenges discussed in the 1992 article included the need to develop techniques using cryofixation and freeze-substitution fixation in order to obtain acceptable preparations for the observation of inclusions in the bodies.

The 1992 article was just part of Ohsumi’s work. One year later Ohsumi and his small lab published another article describing their continued work with yeast mutants and the identification of fifteen genes that lead to defective autophagic body degradation during starvation-induced autophagy (Tsukada and Ohsumi 1993). As described in this article, the genes were identified by using light microscopy to observe yeast vacuole morphology, including any accumulation of autophagic bodies, in about 5,000 mutagenized yeast colonies. The first autophagy defective mutant discovered was named apg1, the apg coming from autophagy. This same continued experiment found an additional fourteen mutants that were also required for autophagy, and all were named using the same apg schema. When exposed to starvation 
conditions, all fifteen mutants showed a lack of accumulated autophagic bodies, experienced defective bulk protein degradation, and quickly lost viability. Additionally, all fifteen resulted in homozygous diploids (those with the recessive genotype of apg/apg; no dominant APG lacking sporulation (growth). The loss of viability under nitrogen starvation backed up the idea of the fundamental, although still unknown, role that protein degradation plays in cell survival. Ohsumi's results proved that autophagy took place in yeast cells, answered any questions as to the similarity between vacuoles and lysosomes, and provided an easy way to research the autophagy process (Takeshige et al. 1992). There were also strong implications for disease research, since this process is necessary to survive starvation (Nobelprize.org "Prize announcement: The Nobel Prize in Physiology or Medicine 2016.”). The discovery of the fifteen genes was a breakthrough both for the identification of the genes as well as the understanding that the process used was thought to not be fully exhaustive, suggesting the existence of additional genes (Tsukada and Ohsumi 1993). By 1998 Ohsumi’s postdoctoral student N. Mizushima had identified the roles of some of the identified autophagy genes, which led to an understanding of almost the entire autophagy pathway (Mizushima, Noda et al. 1998, Mizushima, Sugita et al. 1998; Sedwick 2012). Additional studies grew out of the knowledge of the probable existence of more genes. As discussed in the following section, more genes were indeed discovered.

\section{AFTER OHSUMI}

The fifteen genes identified by Ohsumi and colleagues were classified under the apg system around the time that $\mathrm{M}$. Thumm identified and classified six genes under an aut naming schema, short for autophagy, and Klionsky was identifying and classifying his Cvt genes (Ohsumi 2014). 
In the following years, research into autophagy-related genes grew, and other genes were identified and classified based on various identifiers, with the result being a confusing bundle of autophagy genes with differing names. Eventually a new nomenclature was adopted, and all autophagy-related genes, currently almost 40, were classified as ATG (Ohsumi 2014). Of these nearly forty genes, a subset of seventeen are known to be necessary for the formation of the autophagosome (Fernández et al. 2016).

One of the most interesting aspects of autophagy is that it seems to be a process that has been conserved throughout evolutionary history (Larsson and Masucci 2016). Evidence of this is seen in the fact that research into ATG genes is ongoing, with new genes continuously being found and classified in various forms of life including mammals, yeast, plants, and even ticks (Fernández et al. 2014). In his 2014 review, Ohsumi discusses this idea of evolutionary conservation. He points out that the main function of autophagy is the recycling of proteins and that this is a primary defense mechanism of cellular life. Early recycling of proteins was most likely a less-refined version of the modern autophagy process. He states that there has been a preservation of "the fundamental mechanisms of autophagy" throughout eukaryotes. Kuma and Mizushima (2010) agree that autophagy is a fundamental and evolutionarily conserved role as an adaptation to starvation and did a review discussing the topic. The identification of novel genes in more advanced eukaryotes than yeast, such as C. elegans, suggests that evolution has added autophagy genes for the specialized needs of higher eukaryotes (Meléndez and Levine 2009). Ohsumi's work led to a greater understanding of how cells degrade and recycle material, which in turn showed the critical role of autophagy in health and physiology-ranging from surviving during times of starvation to responding to infection (Nobelprize.org "Press release: The 2016 Nobel Prize in Physiology or Medicine.”). According to Professor Zierath from the Nobel 
Committee, Ohsumi's research led to an understanding of, and further research into, the role of autophagy in normal physiology, embryogenesis, cell division, warding off infections, removing toxic proteins due to aging, and a variety of diseases including Alzheimer's, diabetes, and cancer (Nobelprize.org “Prize announcement: The Nobel Prize in Physiology or Medicine 2016.”).

B. Levine has been researching autophagy-correlated diseases for almost two decades. In 1999 she and colleagues investigated the similarities between the human beclin 1 gene, a gene suspected in some cancers, and the autophagy gene apg6 (Liang et al. 1999). Their results suggested that autophagic genes may play a role in tumorigenesis. A few years later, Levine, Ohsumi, and others published an article showing a direct tie between defective autophagy genetics and the growth of tumors, stating that the gene beclin 1 is in fact also an autophagy gene (Qu et al. 2003). In 2006 Hara et al. investigated the relationship between autophagy and neurodegenerative dis- eases. Their results suggest that autophagy is critical in removing abnormal proteins that have a negative impact on neural function, and thus abnormal autophagy function can lead to neurodegeneration. According to a review by Levine and Kroemer (2008), autophagy’s relationship with neurodegeneration has been shown in relation to diseases such as Alzheimer’s, Parkinson’s, Huntington’s, and transmissible spongiform encephalopathies. Autophagy has also been shown to play a critical role in mammal embryo preimplantation (Tsukamoto et al. 2008). Research into autophagy genes and disease continues to show that mutated autophagy genes and defective autophagy processes cause a variety of diseases, including diseases of the heart, liver, and muscles, as well as diseases associated with aging (Komatsu et al. 2007; Levine and Kroemer 2008; Nobelprize.org "Press release: The 2016 Nobel Prize in Physiology or Medicine.”). Ebrahimi-Fakhari et al. (2016) suggest classifying these diseases as autophagy-related congenital disorders, noting that defects in autophagy genes have a 
diverse effect resulting in a variety of diseases and that the likelihood of discovering even more defects in the future is high.

In regards to the role of the autophagy machinery in infection, there continues to be ongoing research focusing on a variety of pathogens. A recent article has even shown a relationship between autophagy and the Zika virus (Liang et al. 2016). Back in 2004 there were multiple investigations into this topic, focusing on organisms such as group A Streptococcus (Nakagawa et al. 2004) and Mycobacterium tuberculosis (Gutiérrez et al. 2004). Other pathogens found to be destroyed by autophagy, a process sometimes referred to as xenophagy, include: Shigella flexneri, Salmonella enterica, Listeria monocytogenes, Francisella tularensis, herpes simplex virus type I (HSV-1) and other similar viruses, and parasites including Toxoplasma gondii (Levine and Kroemer 2008). A review by Randow and Münz (2012) concluded that autophagy is efficient when it comes to sequestering pathogens that have not evolved to live in the cytosol, such as those that are normally caught out of the cell and sequestered in endosomes (membranebound compartments) but have escaped and end up freely in the cytosol. When it comes to pathogens that are accustomed to the cytosol, they seem to have evolved techniques for avoiding autophagy. This is yet another example of autophagy’s long evolutionary history. Randow and Münz go on to point out research that has shown that ATG proteins are also involved in phagocytosis and exocytosis, both of which play critical roles in the removal of pathogens. Autophagy is a fundamental eukaryotic cellular process that degrades, and recycles, cellular components ranging from proteins to large organelles such as mitochondria and intracellular structures, including pieces of membranes, endoplasmic reticulum (ER), lipid granules, and glycogen granules (Kuma and Mizushima 2010; Takeshige et al. 1992). Some of these structures, such as the glycogen granules, require further research to determine their relationship with 
autophagy. In regards to lipid granules, an article by Singh et al. (2009) reported the discovery of autophagic function in regards to regulating lipid metabolism.

The process plays an essential role in the case of starvation and stress due to its ability to provide recycled materials for the creation of necessities, and it also provides energy for this creation (Nobelprize.org “Press release: The 2016 Nobel Prize in Physiology or Medicine.”). Beyond starvation and stress, autophagy is a critical part of health and physiological functions, including assisting with control of infectious agents, contributing to cell differentiation, and various roles in the prevention and cause of diseases.

\section{BIBLIOGRAPHIC LOOK AT THE SCIENCE}

In the decades between de Duve coining the term autophagy and Ohsumi's successful vacuole imaging, autophagocytosis had been studied and was known to be a part of both normal and damaged or diseased cellular function (Arstila and Trump 1968). Although the amount of research conducted on autophagy was steady, it was not a highly researched area. In his 2014 review, Ohsumi shows that autophagy research was fairly level, and low, until the early 2000s, when B. Levine published her results showing that an autophagy gene played a role in tumor suppression. Since that time, there has been a growing interest in autophagy. A November 10, 2016, search of Web of Science (WoS) for the topic “autophagy” resulted in more than 30,000 items indexed with a time frame that confirms Ohsumi's statements. Of the 30,190 results in Web of Science that appear to be on the topic of autophagy, 218 were published before 1992. Between 1967 and the early 1990s, the number of articles indexed in WoS that relate to the topic of autophagy is steady, ranging from two a year to a maximum of fifteen. After the 1990s the numbers increase, ranging from twenty-eight to finally breaking one hundred in 2001. Since the 
late 2000s the numbers have grown even more, with over 5,000 articles published and indexed on the WoS topic of autophagy in 2015 (see Figure 3).

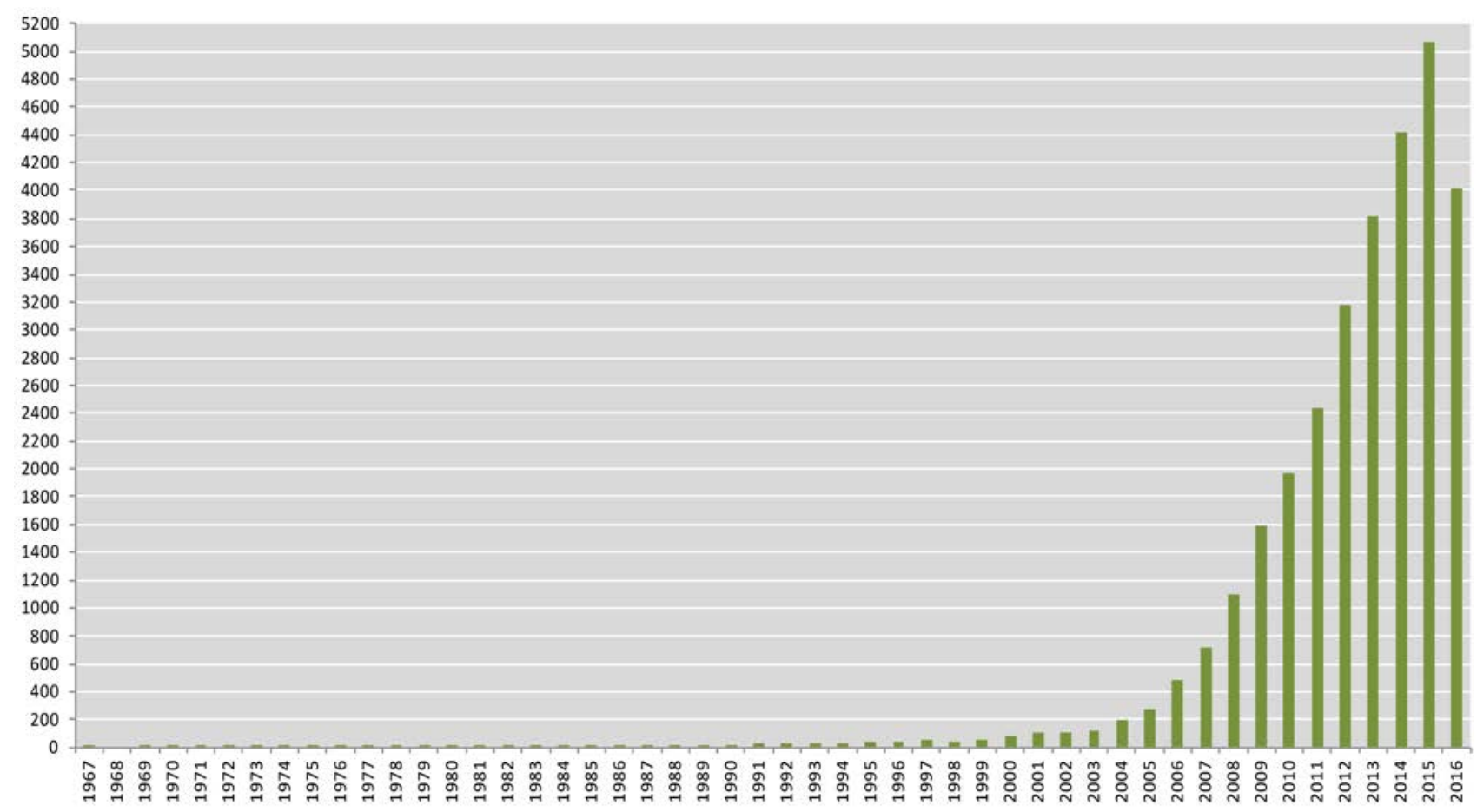

FIGURE 3 The growth of autophagy research over the years shown by the number of autophagy related publications per year. Data source: Web of Science. Retrieved 10 November 2016.

One of the breakthrough outcomes of Ohsumi’s work was the use of yeast to study autophagy. Due to the ease of using and studying yeast cells, they are often used to explore what may be happening in human cells (Nobelprize.org "Press release: The 2016 Nobel Prize in Physiology or Medicine.”). Ohsumi was able to overcome a major challenge of autophagy research on yeastthat of being able to identify and observe autophagy in the small cellular structures of yeast. After this discovery, there was an increase in autophagy research. Compared to the just over 200 autophagy articles published in the twenty- five years after de Duve, there were more than 600 articles published in just the ten years after Ohsumi’s 1992 article. Of these articles, 175 utilized 
yeast cells as the experiment material. The knowledge that was gained from these experiments has led to a better understanding of the autophagy methodology and furthered research on all types of cells.

\section{THE SCIENTIST}

\section{YOSHINORI OHSUMI}

\section{LIFE, EDUCATION, AND CAREER}

Yoshinori was born in Fukoka, Japan, on February 9, 1945. At the University of Tokyo he earned his undergraduate degree in 1967 from the Department of Basic Science, his graduate degree in 1972 from the Department of Biochemistry, and then became a Research Fellow for the Department of Agricultural Chemistry from 1972 to 1974 (Honda 2016). In an interview with the Journal of Cell Biology, Ohsumi states that he had an interest in the natural sciences that became an interest in chemistry during his high school years (Sedwick 2012). During his college years, his interest changed to the new and exciting topic of molecular biology. After his Fellowship at the University of Tokyo, Ohsumi traveled to the United States, where he worked as a postdoctorate student in Dr. Gerald Edelman’s lab at Rockefeller University until 1977 (Honda 2016). About halfway through his time at Rockefeller, Ohsumi switched his focus from E. coli to working on yeast DNA duplication with Mike Jazwinski (Sedwick 2012). This work with Jazwinski began Ohsumi’s work with yeast. After his time at Rockefeller, Ohsumi returned to the University of Tokyo, where he worked in other researchers’ labs until 1988, when he became an associate professor and started a lab of his own (Honda 2016). Since that time, according to his CV, he has been a professor at The National Institute for Basic Biology (19962009); the Graduate University for Advanced Studies (SOKENDAI) (2004-2009); and various 
centers at the Tokyo Institute of Technology since 2009, including the Integrated Research Institute, the Frontier Research Center, and currently the Institute of Innovative Research. Ohsumi has been regarded as a humble and generous researcher who has proven to be both a great mentor for those who have trained in his laboratory and an influence to many others (Enserink and Pennisi 2016). During his interview with Nobelprize.org, Ohsumi expressed his surprise at being a single winner, since so many other researchers are working in the field (Nobelprize.org, “Yoshinori Ohsumi-interview.”). During his Cell interview Ohsumi credited his success to his noncompetitive nature, since he avoided the popular areas of research and instead focused his studies on areas where not many people were working (Sedwick 2012). He also states that he was not very successful for a large part of his career, saying that he had many difficulties that he caused mostly by himself. Shortly after he received news of his Nobel award, Ohsumi gave a short speech where he emphasized multiple times the importance of fundamental science (Associated Press [AP] 2016). He stated that he didn’t begin his research because he knew it would be tied to “cancer and human longevity.” Rather Ohsumi started his research because it was a new area of science where not much was known.

As Ohsumi has stated in interviews and statements, the beginning of his academic career was not remarkable. However, in the past decade or so his work has begun to be recognized, and he has received several awards — at least one award nearly every year since 2005. According to his curriculum vitae, these awards include the 2005 Fujiwara Award, 2006 Japan Academy Prize, 2007 Science Award of the Botanical Society of Japan, 2008 Asahi Prize, 2012 Kyoto Prize from the Inamori Foundation, and a 2013 Thomson Reuters Citation Laureate. In 2015 alone he received the Person of Cultural Merit award, Keio Medical Science Prize, International Prize for Biology, and the Canada Gairdner International Award. Finally, in 2016, he has been awarded 
the 2016 Paul Janssen Award, 15th Wiley Prize, 45th Rosenstiel Award, and of course the 107th Nobel Prize in Physiology or Medicine. This Nobel Prize is the 24th awarded to a Japanese Laureate and only the fourth to a Japanese Physiology or Medicine Laureate (Nobelprize.org “Nobel laureates and country of birth.”).

\section{BIBLIOMETRICS}

Ohsumi has published just under 300 articles that have been indexed in Web of Science (WoS) as of November 3, 2016. Of these, 227 were about autophagy in some form, with some of his most recent work focusing on mitophagy, the autophagy of mitochondria. His most recent publication, “The Intrinsically Disordered Protein Atg13 Mediates Supramolecular Assembly of Autophagy Initiation Complexes,” was published in July of 2016 in the journal Developmental Cell. His very first publication in WoS is from his time as a graduate student working with E. coli. "Inhibitory Effect of Diphtheria Toxin on Amino Acid Incorporation in Escherichia Coli Cell- Free System” was published in the Journal of Bacteriology in 1970 (Tsugawa, Ohsumi, and Kato 1970). During this time Ohsumi was not publishing much, with just four articles published between 1970 and 1981. By 1981 Ohsumi’s publications became primarily yeast focused, with his number of yearly publications increasing. Since he began working with yeast, he publishes every year and demonstrates the growth in publication numbers often seen with successful researchers, reaching a high of twenty-five publications dur- ing 2006 (see Figure 4). His 299 WoS articles have been cited nearly 36,000 times by more than 14,000 articles, averaging almost 120 citations per article. Fewer than 3,000 of those citations are self-citations. Following the growth in interest in autophagy research and the increase in Ohsumi's publications, the number 
of citations to his articles also grows each year (see Figure 5). These numbers give Ohsumi a WoS h-index of 89.

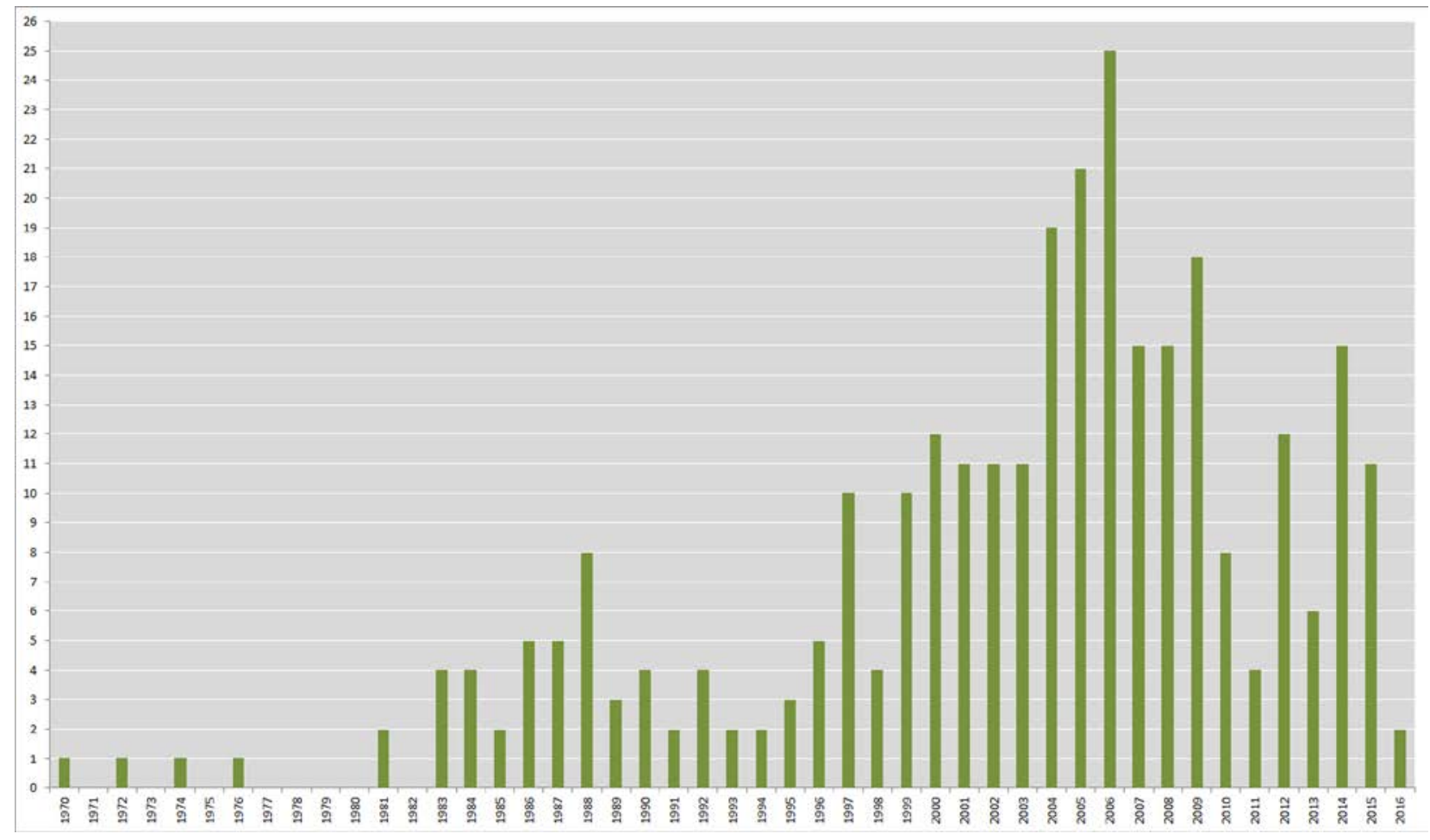

FIGURE 4 Yoshinori Ohsumi, Number of Published Items in Each Year. Data source: Web of Science. Retrieved 3 November 2016. 


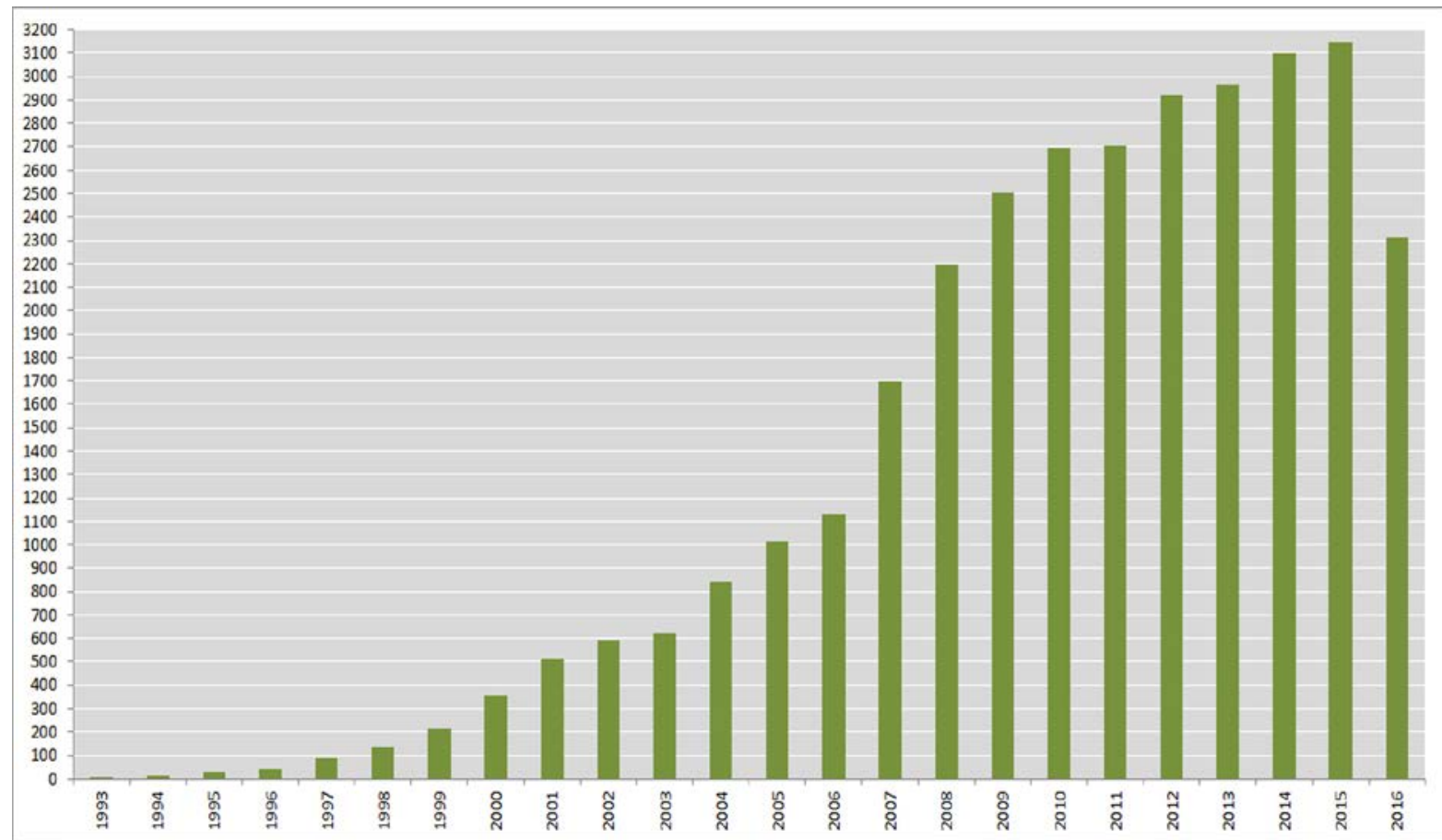

FIGURE 5 Yoshinori Ohsumi, Number of Times Cited in Each Year. Data source: Web of

Science. Retrieved 3 November 2016.

Ohsumi’s most frequently cited article is his 2000 article published in EMBO Journal, “LC3, a Mammalian Homologue of Yeast Apg8p, Is Localized in Autophagosome Membranes after Processing.” This article had 3,246 citations as of November 3, 2016, averaging almost 191 citations a year since its publication. All of his top five cited articles are on autophagy, and all average over seventy-five citations per year (see Table 1). The journal Autophagy, a journal started in 2005 by Kilonsky in response to the growth of autophagy research, is the second most frequently published in journal by Ohsumi (see Table 2) (Ohsumi 2014). The first is the Journal of Biological Chemistry, which has been around for Ohsumi's entire publishing career. 
TABLE 1 Top Five Most Highly Cited Papers by Yoshinori Ohsumi

\begin{tabular}{|c|c|c|}
\hline $\begin{array}{l}\text { Number } \\
\text { of times } \\
\text { cited }\end{array}$ & $\begin{array}{l}\text { Average } \\
\text { citations } \\
\text { per year }\end{array}$ & Citation \\
\hline 3246 & 190.9 & $\begin{array}{l}\text { Kabeya, Y., N. Mizushima, T. Ueno, A. Yamamoto, T. Kirisako, T. Noda, } \\
\text { E. Kominami, Y. Ohsumi, and T. Yoshimori. 2000. LC3, a mammalian } \\
\text { homologue of yeast Apg8p, is localized in autophagosome membranes } \\
\text { after processing. The EMBO journal } 19 \text { (21):5720-5728. }\end{array}$ \\
\hline 1428 & 109.9 & $\begin{array}{l}\text { Kuma, A., M. Hatano, M. Matsui, A. Yamamoto, H. Nakaya, T. Yoshimori, } \\
\text { Y. Ohsumi, T. Tokuhisa, and N. Mizushima. 2004. The role of } \\
\text { autophagy during the early neonatal starvation period. Nature } 432 \\
\text { (7020):1032-1036. }\end{array}$ \\
\hline 1156 & 88.9 & $\begin{array}{l}\text { Mizushima, N., A. Yamamoto, M. Matsui, T. Yoshimori, and Y. Ohsumi. } \\
2004 \text {. In vivo analysis of autophagy in response to nutrient starvation } \\
\text { using transgenic mice expressing a fluorescent autophagosome } \\
\text { marker. Molecular biology of the cell } 15(3): 1101-1111 .\end{array}$ \\
\hline 1079 & 89.9 & $\begin{array}{l}\text { Komatsu, M., S. Waguri, T. Ueno, J. Iwata, S. Murata, I. Tanida, J. Ezaki, } \\
\text { N. Mizushima, Y. Ohsumi, Y. Uchiyama, E. Kominami, K. Tanaka, and } \\
\text { T. Chiba. 2005. Impairment of starvation-induced and constitutive } \\
\text { autophagy in Atg7-deficient mice. The Journal of cell biology } 169 \\
\text { (3):425-434. }\end{array}$ \\
\hline 1067 & 76.2 & $\begin{array}{l}\text { Qu, X., J. Yu, G. Bhagat, N. Furuya, H. Hibshoosh, A. Troxel, J. Rosen, } \\
\text { EL. Eskelinen, N. Mizushima, Y. Ohsumi, G. Cattoretti, and B. Levine. } \\
\text { 2003. Promotion of tumorigenesis by heterozygous disruption of the } \\
\text { beclin } 1 \text { autophagy gene. The Journal of clinical investigation } 112 \\
\text { (12):1809-1820. }\end{array}$ \\
\hline
\end{tabular}

Data source: Web of Science. Retrieved Nov. 3, 2016

TABLE 2 Top Five Journals Published in by Yoshinori Ohsumi

\begin{tabular}{lc}
\hline Journal title & Number of articles \\
\hline Journal of Biological Chemistry & 28 \\
Autophagy & 26 \\
Molecular Biology of the Cell & 18 \\
Journal of Cell Biology & 16 \\
Cell Structure and Function & 11
\end{tabular}

Data source: Web of Science. Retrieved Nov. 3, 2016 


\section{CONCLUSION}

Nobel Laureates are called so as a sign of the great honor it is to have one's work recognized by the award (Nobelprize.org “Facts on the Nobel Prizes in Physiology or Medicine.”). This year’s Physiology or Medicine Laureate is Yoshinori Ohsumi, who “discovered and elucidated mechanisms underlying autophagy, a fundamental process for degrading and recycling cellular components” (Nobelprize.org “Press release: The 2016 Nobel Prize in Physiology or Medicine.”). This process of “degrading and recycling cellular components” is called autophagy. The autophagy process was known before Ohsumi, but its physiological significance, including the degradation of proteins and organelles, was not known (Ohsumi 2014). Ohsumi's work on autophagy opened the door for future research by providing a way to study autophagy in yeast, as well as documenting the basic genetics behind the process.

Autophagy is a critical and evolutionarily contained process that allows our cells to not only remove unneeded or harmful material but also to get needed materials and energy. Disruptions in the process or in the genes have been found to play a role in numerous diseases, including Parkinson's, Alzheimer's as well as other neurological-related diseases, type 2 diabetes, cancer, and a wide variety of genetic diseases. Some of the current autophagy related research focuses on the development of autophagy-targeted drugs for the treatment of different diseases (Nobelprize.org “Press release: The 2016 Nobel Prize in Physiology or Medicine.”). According to Ohsumi’s own 2014 review on autophagy, additional research areas include that of the autophagosome membrane and further analysis of the ATG genes and proteins. 


\section{REFERENCES}

AP. 2016. Nobel Prize in medicine winner: "There is no higher honour" [video]. The Guardian. https://www.theguardian.com/science/video/2016/oct/03/nobel-prize-inmedi cine-winner-yoshinori-ohsumi-theres-no-higher-honour-video (accessed November 10, 2016).

Arstila, A. U., and B. F. Trump. 1968. Studies on cellular autophagocytosis: The formation of autophagic vacuoles in the liver after glucagon administration. The American Journal of Pathology 53 (5): 687-733.

Baba, M., K. Takeshige, N. Baba, and Y. Ohsumi. 1994. Ultrastructural analysis of the autophagic process in yeast: Detection of autophagosomes and their characterization. The Journal of Cell Biology 124 (6): 903-13. doi:10.1083/jcb.124.6.903.

de Duve, C. 1963. The lysosome concept. Ciba Foundation Symposium-Lysosomes. Wiley Online Library.

de Duve, C., B. Pressman, R. Gianetto, R. Wattiaux, and F. Appelmans. 1955. Tissue fractionation studies. 6. Intracellular distribution patterns of enzymes in rat-liver tissue. Biochemical Journal 60 (4): 604-17. doi:10.1042/bj0600604.

de Duve, C., and R. Wattiaux. 1966. Functions of lysosomes. Annual Review of Physiology 28 (1): 435-92. doi:10.1146/annurev.ph.28.030166.002251.

Deter, R. L., P. Baudhuin, and C. de Duve. 1967. Participation of lysosomes in cellular autophagy induced in rat liver by glucagon. The Journal of Cell Biology 35 (2): C11-C16. doi:10.1083/jcb.35.2.C11.

Ebrahimi-Fakhari, D., A. Saffari, L. Wahlster, J. Lu, S. Byrne, G. F. Hoffmann, H. Jungbluth, and M. Sahin. 2016. Congenital disorders of autophagy: An emerging novel class of inborn errors of neuro-metabolism. Brain 139 (2): 317-37. doi:10.1093/brain/awv371.

Enserink, M., and E. Pennisi. 2016. Nobel honors discoveries in how cells eat themselves. Science 354 (6308): 20. doi:10.1126/science.354.6308.20.

Fernández, J. M. F., C. P. B. Álvarez, C. V. S. Hernández, E. P. Camberos, C. G. Castillo, D. O. Sahagun, and M. M. Velázquez. 2016. Molecular characterization and expression analysis of three novel autophagy-related genes from the cattle tick Rhipicephalus (Boophilus) microplus (Acari: Ixodidae). Parasitology 143 (13): 1802-09. doi:10.1017/50031182016001542.

Fernández, J. M. F., A. G. Ortega, R. R. Cruz, E. P. Camberos, A. H. Álvarez, and M. M. Velázquez. 2014. Molecular cloning and characterization of two novel autophagyrelated genes belonging to the ATG8 family from the cattle tick Rhipicephalus (Boophilus) micro- plus (Acari: Ixodidae). Experimental and Applied Acarology 64 (4): 533-42. doi:10.1007/ s10493-014-9838-3.

Gutiérrez, M. G., S. S. Master, S. B. Singh, G. A. Taylor, M. I. Colombo, and V. Deretic. 2004. Autophagy is a defense mechanism inhibiting BCG and Mycobacterium tuberculosis survi- val in infected macrophages. Cell 119 (6): 753-66. doi:10.1016/j.cell.2004.11.038.

Hara, T., K. Nakamura, M. Matsui, A. Yamamoto, Y. Nakahara, R. Suzuki-Migishima, M.Yokoyama, K. Mishima, I. Saito, and H. Okano. 2006. Suppression of basal autophagy in neural cells causes neurodegenerative disease in mice. Nature 441 (7095): 885-89. doi:10.1038/nature04724.

Harding, T. M., A. HefnerGravink, M. Thumm, and D. J. Klionsky. 1996. Genetic and phenotypic overlap between autophagy and the cytoplasm to vacuole protein targeting pathway. Journal of Biological Chemistry 271 (30): 17621-24. 
doi:10.1074/jbc.271.30.17621. Honda, M. 2016. Yoshinori Ohsumi. Tokyo Institute of Technology. http://www.ohsumilab.aro.iri.titech.ac.jp/ohsumieng.html (accessed November 10, 2016).

Hutchins, M. U., and D. J. Klionsky. 2001. Vacuolar localization of oligomeric $\alpha-$ mannosidase requires the cytoplasm to vacuole targeting and autophagy pathway components in Saccharomyces cerevisiae. Journal of Biological Chemistry 276 (23): 20491-98. doi:10.1074/jbc.M101150200.

Kabeya, Y., N. Mizushima, T. Ueno, A. Yamamoto, T. Kirisako, T. Noda, E. Kominami, Y. Ohsumi, and T. Yoshimori. 2000. LC3, a mammalian homologue of yeast Apg8p, is localized in autophagosome membranes after processing. The EMBO Journal 19 (21): 5720-28. doi:10.1093/emboj/19.21.5720.

Komatsu, M., S. Waguri, M. Koike, Y.-S. Sou, T. Ueno, T. Hara, N. Mizushima, J.-I. Iwata, J. Ezaki, and S. Murata. 2007. Homeostatic levels of p62 control cytoplasmic inclusion bodyformation in autophagy-deficient mice. Cell 131 (6): 1149-63. doi:10.1016/j. cell.2007.10.035.

Kuma, A., and N. Mizushima. 2010. Physiological role of autophagy as an intracellular recycling system: With an emphasis on nutrient metabolism. Seminars in Cell \& Developmental Biology 21: 683-90. doi:10.1016/j.semcdb.2010.03.002.

Larsson, N.-G., and M. G. Masucci. 2016. Scientific background: Discoveries of mechanisms for autophagy. Nobel Media AB 2014.

Levine, B., and G. Kroemer. 2008. Autophagy in the pathogenesis of disease. Cell 132 (1): 27-42. doi:10.1016/j.cell.2007.12.018.

Liang, Q., Z. Luo, J. Zeng, W. Chen, S.-S. Foo, S.-A. Lee, J. Ge, S. Wang, S. A. Goldman, B. V. Zlokovic, Z. Zhao, and J. U. Jung. 2016. Zika virus NS4A and NS4B proteins deregulate Akt-mTOR signaling in human fetal neural stem cells to inhibit neurogenesis and induce autophagy. Cell Stem Cell 19 (5): 663-71. doi:10.1016/j.stem.2016.07.019.

Liang, X. H., S. Jackson, M. Seaman, K. Brown, B. Kempkes, H. Hibshoosh, and B. Levine. 1999. Induction of autophagy and inhibition of tumorigenesis by beclin 1 . Nature 402 (6762): 672-76. doi:10.1038/45257.

Meléndez, A., and B. Levine. 2009. “Autophagy in C. elegans.” Wormbook: The online review of C. elegans biology. doi:10.1895/wormbook.1.147.1.

Mizushima, N., T. Noda, T. Yoshimori, Y. Tanaka, T. Ishii, M. D. George, D. J. Klionsky, M. Ohsumi, and Y. Ohsumi. 1998. A protein conjugation system essential for autophagy. Nature 395 (6700): 395-98. doi:10.1038/26506.

Mizushima, N., H. Sugita, T. Yoshimori, and Y. Ohsumi. 1998. A new protein conjugation system in human: The counterpart of the yeast Apg12p conjugation system essential for autophagy. Journal of Biological Chemistry 273 (51): 33889-92. doi:10.1074/ jbc.273.51.33889.

Mortimore, G. E., N. J. Hutson, and C. A. Surmacz. 1983. Quantitative correlation between proteolysis and macro- and microautophagy in mouse hepatocytes during starvation and refeeding. Proceedings of the National Academy of Sciences 80 (8): 217983. doi:10.1073/ pnas.80.8.2179.

Mortimore, G. E., and W. F. Ward. 1975. Behavior of the lysosomal system during organ perfusion. An inquiry into the mechanism of hepatic proteolysis. Frontiers of Biology 45: 157-84.

Nakagawa, I., A. Amano, N. Mizushima, A. Yamamoto, H. Yamaguchi, T. Kamimoto, A. Nara, J. Funao, M. Nakata, and K. Tsuda. 2004. Autophagy defends cells against invading group A Streptococcus. Science 306 (5698): 1037-40. doi:10.1126/science.1103966. 
Nakatogawa, H., K. Suzuki, Y. Kamada, and Y. Ohsumi. 2009. Dynamics and diversity in autophagy mechanisms: Lessons from yeast. Nature Reviews Molecular Cell Biology 10 (7): 458-67. doi:10.1038/nrm2708.

Nobelprize.org. Christian de Duve_Facts. Nobel Media AB 2014. http://www.nobelprize.org/ nobel_prizes/medicine/laureates/1974/duve-facts.html (accessed October 18, 2016).

Nobelprize.org. Facts on the Nobel Prizes in Physiology or Medicine. Nobel Media AB 2014. http://www.nobelprize.org/nobel_prizes/facts/medicine/index.html (accessed October 18, 2016). Nobelprize.org. Nobel laureates and country of birth. Nobel Media AB 2014. http://www.nobelprize.org/nobel_prizes/lists/countries.html (accessed October 18, 2016).

Nobelprize.org. Press release: The 2016 Nobel Prize in Physiology or Medicine. Nobel Media AB 2014.

http://www.nobelprize.org/nobel_prizes/medicine/laureates/2016/press.html (accessed October 17, 2016).

Nobelprize.org. Press release: The Nobel Prize in Chemistry 2004. Nobel Media AB 2014. http:// www.nobelprize.org/nobel_prizes/chemistry/laureates/2004/press.html (accessed November 8, 2016).

Nobelprize.org. Prize announcement: The Nobel Prize in Physiology or Medicine 2016. Nobel Media AB 2014. http://www.nobelprize.org/nobel_prizes/medicine/laureates/2016/ announcement.html (accessed November 8, 2016).

Nobelprize.org. Yoshinori Ohsumi-interview. Nobel Media AB 2014. http://www.nobelprize. org/nobel_prizes/medicine/laureates/2016/ohsumi-interview.html (accessed November 16, 2016).

Ohsumi, Y. 2014. Historical landmarks of autophagy research. Cell Research 24 (1): 923. doi:10.1038/cr.2013.169.

Pfeifer, U., and M. Warmuth-Metz. 1983. Inhibition by insulin of cellular autophagy in proximal tubular cells of rat kidney. American Journal of Physiology-Endocrinology and Metabolism 244 (2): E109-E114.

Qu, X. P., J. Yu, G. Bhagat, N. Furuya, H. Hibshoosh, A. Troxel, J. Rosen, E. L. Eskelinen, N.Mizushima, Y. Ohsumi, G. Cattoretti, and B. Levine. 2003. Promotion of tumorigenesis by heterozygous disruption of the beclin 1 autophagy gene. Journal of Clinical Investigation 112 (12): 1809-20. doi:10.1172/jci200320039.

Randow, F., and C. Münz. 2012. Autophagy in the regulation of pathogen replication and adaptive immunity. Trends in Immunology 33 (10): 475-87. doi:10.1016/j.it.2012.06.003. Sedwick, C. 2012. Yoshinori Ohsumi: Autophagy from beginning to end. The Journal of Cell Biology 197 (2): 164-65. doi:10.1083/jcb.1972pi.

Singh, R., S. Kaushik, Y. Wang, Y. Xiang, I. Novak, M. Komatsu, K. Tanaka, A. M. Cuervo, and M. J. Czaja. 2009. Autophagy regulates lipid metabolism. Nature 458 (7242): 1131-35. doi:10.1038/nature07976.

Takeshige, K., M. Baba, S. Tsuboi, T. Noda, and Y. Ohsumi. 1992. Autophagy in yeast demonstrated with proteinase-deficient mutants and conditions for its induction. The Journal of Cell Biology 119 (2): 301-11. doi:10.1083/jcb.119.2.301.

Thumm, M., R. Egner, B. Koch, M. Schlumpberger, M. Straub, M. Veenhuis, and D. H.Wolf. 1994. Isolation of autophagocytosis mutants of Saccharomyces cerevisiae . FEBS Letters 349 (2): 275-80. doi:10.1016/0014-5793(94)00672-5.

Tsugawa, A., Y. Ohsumi, and I. Kato. 1970. Inhibitory effect of diphtheria toxin on aminoacid incorporation in Escherichia coli cell-free system. Journal of Bacteriology 104 (1): 152. Tsukada, M., and Y. Ohsumi. 1993. Isolation and characterization of autophagy-defective mutants of Saccharomyces cerevisiae. FEBS Letters 333 (1-2): 16974. doi:10.1016/0014-5793(93)80398-E. 
Tsukamoto, S., A. Kuma, M. Murakami, C. Kishi, A. Yamamoto, and N. Mizushima. 2008. Autophagy is essential for preimplantation development of mouse embryos. Science 321 (5885): 117-20. doi:10.1126/science.1154822.

Wiemken, A., M. Schellenberg, and K. Urech. 1979. Vacuoles: The sole compartments of digestive enzymes in yeast (Saccharomyces cerevisiae)? Archives of Microbiology 123 (1): 23-35. doi:10.1007/BF00403499.

Yamamoto, H., Y. Fujioka, S. W. Suzuki, D. Noshiro, H. Suzuki, C. Kondo-Kakuta, Y. Kimura, H. Hirano, T. Ando, N. N. Noda, and Y. Ohsumi. 2016. The intrinsically disordered protein Atg13 mediates supramolecular assembly of autophagy initiation com- plexes. Developmental Cell 38 (1): 86-99. doi:10.1016/j.devcel.2016.06.015. 